\title{
ERRATUM
}

\section{RasGRF suppresses Cdc42-mediated tumour cell movement, cytoskeletal dynamics and transformation}

\section{Fernando Calvo, Victoria Sanz-Moreno, Lorena Agudo-Ibáñez, Fredrik Wallberg, Erik Sahai, Christopher J. Marshall and Piero Crespo}

Nat. Cell Biol. 13, 819-826 (2011); published online 19 June 2011; corrected after print 15 July 2011

In the version of this article initially published online and in print, the panel on the lower right-hand side of Fig. 3a corresponding to the anti-SOS blot was incorrectly duplicated and shown in place of the anti-Cdc42 blot. The correct panels are shown below. These errors have also been corrected in the HTML and PDF versions of the article.

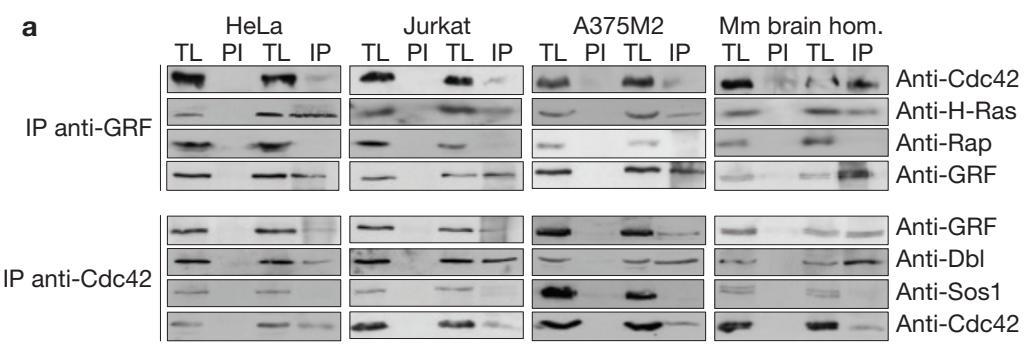

